\title{
The impact of a multidisciplinary blood conservation protocol on patient outcomes and cost after cardiac surgery
}

\author{
Niv Ad, MD, ${ }^{\text {a }}$ Sari D. Holmes, PhD, ${ }^{a}$ Jay Patel, BS, ${ }^{\mathrm{b}}$ Deborah J. Shuman, BS, ${ }^{\mathrm{b}}$ Paul S. Massimiano, MD, \\ Elmer Choi, MD, ${ }^{b}$ David Fitzgerald, CCP, ${ }^{\mathrm{d}}$ Linda Halpin, RN, MSN, ${ }^{\mathrm{b}}$ and Lisa M. Fornaresio, PhD ${ }^{\mathrm{a}}$
}

\begin{abstract}
Objective: Although associations between transfusion and inferior outcomes have been documented, there is a lack of blood transfusion standardization in cardiac surgery. At the Inova Heart and Vascular Institute, a multidisciplinary, criterion-driven algorithm for transfusion management was implemented. We examined the effect of our blood conservation protocol on transfusion rates and outcomes after cardiac surgery and on stability of transfusion over time.
\end{abstract}

Methods: Patients undergoing first-time cardiac surgery from 2006 (full year before protocol) were compared with those in 2009 (after protocol) and propensity score matched to improve balance. Data were prospectively collected. Stability of transfusion incidence also was compared (2005-2006 vs 2008-2014).

Results: After matching, 890 patients from each year were included. Use of blood products decreased from $54 \%$ in 2006 to $25 \%$ in $2009(P<.001)$. Patients in 2009 had a lower incidence of postoperative renal failure $(2.6 \%$ vs $4 \%, P=.04)$, reoperations for bleeding ( $2 \%$ vs $4 \%, P=.004)$, and readmissions at less than 30 days $(6 \%$ vs $12 \%, P<.001)$. No differences were found for operative mortality, deep sternal wound infection, or permanent strokes. Patients in 2009 had greater improvement in physical $(P=.001)$ and mental $(P=.02)$ quality of life than patients in 2006. Reduction of blood products led to significant cost savings for packed erythrocytes $(P<.001)$ and platelets $(P<.001)$. After protocol implementation, transfusion incidence remained $30 \%$ or less, with less than $28 \%$ in most years.

Conclusions: A multidisciplinary blood conservation program can significantly control blood transfusion rates, improve outcomes, and be sustained over time. Efforts are needed to implement evidence-based protocols to standardize and decrease blood use in cardiac surgery to improve outcomes and reduce cost. (J Thorac Cardiovasc Surg 2017;153:597-605)

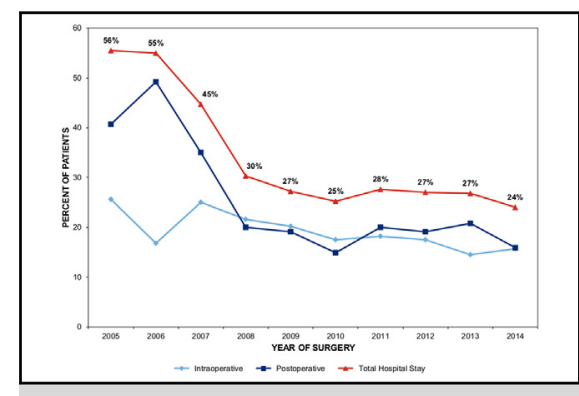

Incidence of blood product transfusion before and after implementation of blood protocol.

\section{Central Message}

A multidisciplinary blood conservation program can control blood transfusion, improve outcomes, and be sustained over time.

\section{Perspective}

Adherence to standardized blood conservation protocols had a positive effect on postoperative outcomes of patients undergoing cardiac surgery. Cardiac surgery programs should consider measuring transfusion indications and rates as indicators of quality. Communication and involvement from all clinicians involved in cardiac surgical cases are key to success of a blood conservation protocol.

See Editorial Commentary page 606.
Cardiac surgery accounts for a significant proportion of all blood products transfused in the United States. ${ }^{1,2}$ Data from the Society of Thoracic Surgeons (STS) database indicate that up to $50 \%$ of patients undergoing cardiac surgery receive blood transfusion. ${ }^{3}$ As these patients continue to

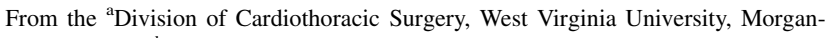
town, WVa; ${ }^{b}$ Inova Fairfax Hospital, Falls Church, Va; ${ }^{c}$ Cardiovascular Surgery, Washington Adventist Hospital, Takoma Park, Md; and ${ }^{\mathrm{d}}$ Division of Cardiovascular Perfusion, The Medical University of South Carolina, Charleston, SC.

Received for publication May 23, 2016; revisions received Sept 15, 2016; accepted for publication Oct 7, 2016; available ahead of print Dec 6, 2016.

Address for reprints: Niv Ad, MD, Division of Cardiothoracic Surgery, West Virginia University, 1 Medical Center Drive, Morgantown, WV 26506 (E-mail: niv.ad@ wvumedicine.org)

$0022-5223 / \$ 36.00$

Copyright (C) 2016 by The American Association for Thoracic Surgery http://dx.doi.org/10.1016/j.jtcvs.2016.10.083
}

present with increasing complexity and acuity, these rates can be expected to increase. ${ }^{4-6}$

Despite the existence of guidelines from numerous national and international organizations for perioperative blood transfusion, ${ }^{7-15}$ wide discrepancies persist with regard to blood transfusions, not only among institutions but also among key decision makers (eg, surgeons and anesthesiologists). ${ }^{16-22}$ The recommendations that do exist are based chiefly on expert opinion rather than verifiable

Scanning this QR code will take you to supplemental figure for this article.

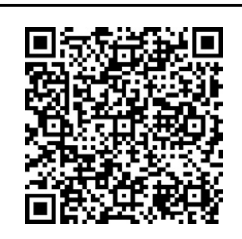




\section{Abbreviations and Acronyms \\ $\mathrm{CABG}=$ coronary artery bypass grafting \\ $\mathrm{HgB}=$ hemoglobin \\ $\mathrm{RBC}=$ red blood cell \\ STS $=$ Society of Thoracic Surgeons}

evidence. $^{10,11,23}$ This state of affairs suggests that many transfusions may be unnecessary and reflects the general uncertainty in determining the need for transfusion, including the role of hemoglobin $(\mathrm{HgB})$ levels and clinical assessment in the decision to transfuse. ${ }^{18-20,24,25}$

Beginning in mid-2007, a multidisciplinary team at the Inova Heart and Vascular Institute began to develop a blood conservation protocol to lower transfusion rates and establish a uniform transfusion standard across our cardiac surgery program. This comprehensive, criterion-driven algorithm for transfusion included modifications to cardiopulmonary bypass techniques, anesthesia, management of bleeding, and clear criteria for transfusion. The purpose of this study was to examine the impact of our institutional protocol on blood use and patient outcomes and the stability of blood use after the protocol was implemented.

\section{MATERIALS AND METHODS Patients}

The study sample comprised patients who underwent cardiac surgery at the Inova Heart and Vascular Institute before and after the implementation of a blood conservation protocol that was developed in 2007. The changes in clinical practice that took place because of this protocol did not occur all at once, but rather were incrementally instituted throughout the year of 2007 and into 2008. Therefore, we examined patients who underwent surgery in 2009 , when the blood conservation protocol had been fully in place and adhered to for a complete year, and compared them with similar patients who underwent surgery in 2006, the year before the protocol was developed.

The primary outcomes of interest included blood product use, clinical complications and survival, and cost. Secondary outcome analyses examined the degree to which the protocol had been implemented and adhered to from 2008 to 2014 in relation to the incidence of blood use from 2005 to 2007, before the protocol was developed. All patient outcome data were collected prospectively and obtained from our local STS database and institutional cardiac surgery database. Data on mortality during follow-up were updated through the use of the National Death Index, the Social Security Death Index, patients' medical records, and information from family members. Cost data for blood products were available from our institutional finance department. The study was approved by our institutional review board (study 6.022 and 12.055).

\section{Blood Conservation Protocol}

To facilitate a reduction in blood use, the Inova Heart and Vascular Institute developed and implemented a multifaceted blood conservation protocol over the course of the year 2007. Principal among the changes in perfusion practice were the expanded use of cell salvage blood in place of cardiotomy suction, the widespread adoption of acute normovolemic hemodilution, and the routine use of retrograde autologous priming of the cardiopulmonary bypass circuit.

At the time that the changes in perfusion practice took place, a criterion-driven algorithm for blood transfusion was developed with the input of a multidisciplinary team of clinical nurses, anesthesiologists, cardiac surgeons, and physician assistants. This algorithm was developed in conjunction with the 2007 STS guidelines ${ }^{8}$ and is outlined in Figure 1. According to the protocol, intraoperative blood transfusion is performed only for an $\mathrm{HgB}$ level less than $6 \mathrm{~g} / \mathrm{dL}$ or a hematocrit level less than $18 \%$ in the presence of clinical indices of malperfusion. Likewise, an $\mathrm{HgB}$ level less than $7 \mathrm{~g} / \mathrm{dL}$ or a hematocrit level less than $21 \%$ postoperatively with suggestive clinical indices may prompt a transfusion.

The multidisciplinary team comprises cardiac surgeons, anesthesiologists, intensivists, nurses along the service line, and perfusionists, all of whom are familiar with the blood conservation protocol and are in communication with each other about each surgical case. In all instances, the decision to transfuse blood is ultimately made solely at the discretion of the attending cardiac surgeon.

\section{Statistical Analysis}

Continuous data are presented as mean \pm standard deviation, and categorical data are presented as frequency (percent) unless otherwise noted. A $P$ value $<.05$ was considered statistically significant. All analyses were conducted using SPSS version 17.0 (SPSS Inc, Chicago, Ill). To determine differences in preoperative characteristics of patients in 2006 and 2009, the chi-squared or Fisher exact tests were used for categorical variables and Student independent-samples $t$ test was used for continuous measures. Patients who underwent surgery in 2009 were propensity score matched to patients in 2006 to simulate randomization and improve balance on preoperative clinical and demographic variables. ${ }^{26,27} \mathrm{~A}$ logistic model was used to create propensity scores (c statistic $=0.622$ ) that included the following covariates selected a priori: age, gender, body mass index, ejection fraction, diabetes, chronic pulmonary disease, peripheral vascular disease, previous cardiovascular intervention (including prior surgery), congestive heart failure, emergency status, dialysis, triple-vessel disease, hypertension, coronary artery bypass grafting (CABG) surgery, valve surgery, surgical ablation, and cardiopulmonary bypass time. A caliper of 0.25 propensity score standard deviations was used to match patients in 2009 and 2006. The matching procedure was successful in improving balance between the 2 groups (Figure E1), and most covariates achieved more than $70 \%$ improvement. All further analyses used the propensity score-matched patients $(n=890$ in each group).

Differences in perioperative and postoperative outcomes by group were evaluated using the chi-squared or Fisher exact test for categorical variables and Student independent-samples $t$ test for continuous measures, except when the Mann-Whitney test was used because of heterogeneity of variance. For units of blood products, groups were created because of the highly skewed and zero-inflated nature of these data (0 units, 1-2 units, 3-5 units, and 6+ units), and chi-squared tests were conducted for comparison between surgery year groups. For similar reasons, groups were created for red blood cells (RBCs) $(0$ USD, $<450$ USD, and $\geq 450$ USD) and platelet (0 USD, $\leq 1750$ USD, and $>1750$ USD) cost data. Kaplan-Meier analysis with the log-rank test was conducted to compare cumulative survival curves between the 2 groups.

\section{RESULTS}

\section{Patient Characteristics}

A total of 2041 patients who received cardiac surgery in 2006 or 2009 were identified for analysis. These 2 cohorts 


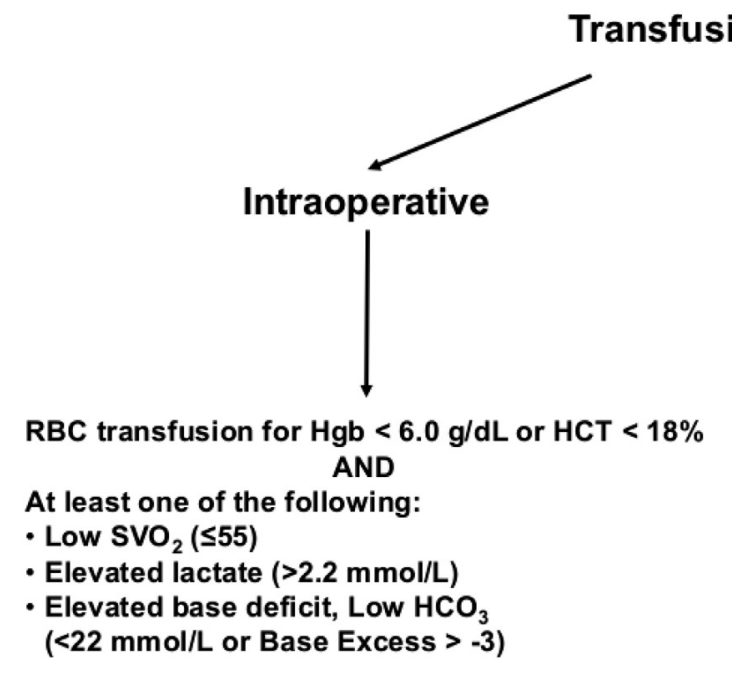

FIGURE 1. Flow diagram of institutional blood conservation protocol. $R B C$, Red blood cell; $H g b$, hemoglobin; $H C T$, hematocrit; $S V O_{2}$, venous blood oxygen saturation; $\mathrm{HCO}_{3}$, bicarbonate. Reprinted with permission from Ad N, Massimiano PS, Burton NA, Halpin L, Pritchard G, Shuman DJ, Holmes SD. Effect of patient age on blood product transfusion after cardiac surgery. J Thorac Cardiovasc Surg. 2015;150:209-14.

differed significantly in relation to several preoperative variables (Table 1). The groups became balanced on all preoperative characteristics after propensity score matching was applied to simulate randomization (Table 2).

TABLE 1. Baseline patient characteristics before propensity score matching

\begin{tabular}{lccc}
\hline \multicolumn{1}{c}{ Characteristic ${ }^{*}$} & $\begin{array}{c}\text { Year 2006 } \\
(\mathbf{n = 1 0 9 7 )}\end{array}$ & $\begin{array}{c}\text { Year 2009 } \\
(\mathbf{n}=\mathbf{9 4 4})\end{array}$ & $\begin{array}{c}\boldsymbol{P} \\
\text { value }\end{array}$ \\
\hline Age, y & $62.8 \pm 12.2$ & $63.3 \pm 11.7$ & .44 \\
Female & $275(25)$ & $271(29)$ & .06 \\
Body mass index $\left(\mathrm{kg} / \mathrm{m}^{2}\right)$ & $28.3 \pm 5.4$ & $29.3 \pm 5.9$ & $<.001$ \\
Congestive heart failure & $191(17)$ & $217(23)$ & .002 \\
Dialysis & $28(3)$ & $30(3)$ & .40 \\
Preoperative creatinine level (mg/dL) & $1.2 \pm 1.0$ & $1.3 \pm 1.1$ & .18 \\
Cerebrovascular disease & $139(13)$ & $126(13)$ & .65 \\
Peripheral vascular disease & $110(10)$ & $98(10)$ & .79 \\
Diabetes & $346(32)$ & $305(32)$ & .71 \\
Hypertension & $746(68)$ & $722(77)$ & $<.001$ \\
Triple-vessel disease & $611(56)$ & $499(53)$ & .20 \\
Previous cardiovascular intervention & $252(23)$ & $253(27)$ & .05 \\
Chronic lung disease & $152(14)$ & $197(21)$ & $<.001$ \\
Ejection fraction (\%) & $54 \pm 12$ & $55 \pm 12$ & .15 \\
Emergency status & $61(6)$ & $26(3)$ & .002 \\
euroSCORE (additive) & $5.5 \pm 3.6$ & $5.6 \pm 3.5$ & .81 \\
CABG & $808(74)$ & $630(67)$ & $<.001$ \\
Valve & $362(33)$ & $380(40)$ & $<.001$ \\
Surgical ablation & $89(8)$ & $85(9)$ & .47 \\
Cardiopulmonary bypass time & $118.0 \pm 53.4$ & $115.7 \pm 50.7$ & .32 \\
\hline
\end{tabular}

euroSCORE, European System for Cardiac Operative Risk Evaluation; $C A B G$, coronary artery bypass grafting. *Data are presented as mean \pm standard deviation or $\mathrm{N}(\%)$.

\section{Clinical Outcomes}

The incidence of overall blood product transfusion in the matched sample decreased from $54 \%$ in 2006 to $25 \%$ in 2009 (chi-squared $=166.4, P<.001$ ). Notably, the reduction in transfusion was driven by changes in the postoperative period. The incidence of postoperative blood transfusion decreased from $48 \%$ in 2006 to $17 \%$ in 2009 (chi-squared $=205.4, P<.001$ ). However, the frequencies of intraoperative blood transfusion in 2006 and 2009 were not significantly different $(16 \%$ vs $18 \%$; chi-squared $=0.68, P=.41$ ). In addition, there were fewer patients in 2006 who received zero units of RBCs than patients in $2009(55 \%$ vs $79 \%$, chisquared $=117.3, P<.001)$ and more patients in 2006 than 2009 who received 1 to 2 units $(26 \%$ vs $11 \%$, chi-squared $=66.9, P<.001), 3$ to 5 units $(13 \%$ vs $6 \%$, chi-squared $=24.2, P<.001)$, and $6+\mathrm{RBC}$ units $(6 \%$ vs $4 \%$, chi-squared $=4.7, P=.030)$. Likewise, for non-RBC units, fewer patients in 2006 received zero units than patients in 2009 (57\% vs $84 \%$, chisquared $=151.5, P<.001)$ and more patients in 2006 than 2009 who received 1 to 2 units $(17 \%$ vs $6 \%$, chi-squared $=57.8, P<.001), 3$ to 5 units $(12 \%$ vs $4 \%$, chi-squared $=35.1, P<.001)$, and $6+$ non-RBC units $(14 \%$ vs $7 \%$, chi-squared $=28.0, P<.001)$.

Median length of stay was significantly shorter for the 2009 cohort than for the 2006 cohort (median [interquartile range] $=4$ [4] days vs 5 [4] days, $Z=-5.5$, $P<.001)$. Furthermore, the incidence of hospital readmission within 30 days of surgery for the 2006 patients was double that for the 2009 patients $(12 \%$ vs $6 \%$, $P<.001)$. Among the 2009 cohort, the incidence of 
TABLE 2. Baseline patient characteristics after propensity score matching

\begin{tabular}{|c|c|c|c|c|}
\hline Characteristic* & $\begin{array}{l}\text { Year } 2006 \\
(n=890)\end{array}$ & $\begin{array}{l}\text { Year 2009 } \\
(n=890)\end{array}$ & $P$ value & Standardized difference \\
\hline Age, y & $62.8 \pm 12.1$ & $63.2 \pm 11.6$ & .53 & 0.034 \\
\hline Female & $242(27)$ & $244(27)$ & .92 & 0.004 \\
\hline Body mass index $\left(\mathrm{kg} / \mathrm{m}^{2}\right)$ & $28.7 \pm 5.6$ & $29.0 \pm 5.6$ & .33 & 0.054 \\
\hline Congestive heart failure & $167(19)$ & $189(21)$ & .19 & 0.060 \\
\hline Dialysis & $27(3)$ & $25(3)$ & .78 & -0.012 \\
\hline Preoperative creatinine level $(\mathrm{mg} / \mathrm{dL})$ & $1.2 \pm 1.1$ & $1.2 \pm 1.0$ & .77 & 0.010 \\
\hline Cerebrovascular disease & $115(13)$ & $117(13)$ & .89 & 0.006 \\
\hline Peripheral vascular disease & $99(11)$ & $90(10)$ & .49 & 0.032 \\
\hline Diabetes & $288(32)$ & $285(32)$ & .88 & -0.009 \\
\hline Hypertension & $650(73)$ & $670(75)$ & .28 & 0.052 \\
\hline Triple-vessel disease & $479(54)$ & $478(54)$ & .96 & -0.002 \\
\hline Previous cardiovascular intervention & $214(24)$ & $228(26)$ & .44 & 0.037 \\
\hline Chronic lung disease & $139(16)$ & $171(19)$ & .05 & 0.079 \\
\hline Ejection fraction $(\%)$ & $54 \pm 12$ & $54 \pm 12$ & .92 & 0.008 \\
\hline Emergency status & $25(3)$ & $26(3)$ & .89 & 0.006 \\
\hline euroSCORE (additive) & $5.47 \pm 3.54$ & $5.48 \pm 3.45$ & .95 & 0.003 \\
\hline CABG & $625(70)$ & $612(69)$ & .50 & -0.030 \\
\hline Valve & $325(37)$ & $340(38)$ & .46 & 0.035 \\
\hline Surgical ablation & $77(9)$ & $77(9)$ & $>.999$ & 0.000 \\
\hline Cardiopulmonary bypass time & $116.2 \pm 49.5$ & $116.1 \pm 51.4$ & .96 & -0.002 \\
\hline
\end{tabular}

euroSCORE, European System for Cardiac Operative Risk Evaluation; CABG, coronary artery bypass grafting. *Data are presented as mean \pm standard deviation or $\mathrm{N}(\%)$.

postoperative renal failure was lower $(2.6 \%$ vs $4 \%$, chisquared $=4.3, P=.04$ ), and of those patients who developed renal failure, fewer required dialysis $(0.9 \%$ vs $3 \%, P=.007)$. The 2009 cohort also had significantly fewer reoperations for bleeding $(2 \%$ vs $4 \%$, $P=.004)$. After RBC and non-RBC units were controlled for, patients in 2006 still had 2 times greater risk for 30-day readmissions (odds ratio, 2.07; 95\% confidence interval, 1.47-2.90; $P<.001)$ and reoperations for bleeding (odds ratio, 2.38; 95\% confidence interval, $1.26-4.49 ; P=.008)$ than the patients in 2009.

TABLE 3. Comparison of postoperative complications among 2006 and 2009 patients after propensity score matching*

\begin{tabular}{lccc}
\hline \multicolumn{1}{c}{ Complication } & $\begin{array}{c}\text { Year 2006 } \\
\mathbf{n = 8 9 0}\end{array}$ & $\begin{array}{c}\text { Year 2009 } \\
\mathbf{n = 8 9 0}\end{array}$ & $\boldsymbol{P}$ value \\
\hline Permanent stroke & $10(1)$ & $10(1)$ & $>.999$ \\
Pneumonia & $22(3)$ & $19(2)$ & .64 \\
Deep sternal wound infection & $3(0.3)$ & $4(0.4)$ & .73 \\
Renal failure & $39(4)$ & $23(3)$ & .04 \\
$\quad$ Requiring dialysis & $24(3)$ & $8(0.9)$ & .007 \\
Reoperation for bleeding & $39(4)$ & $17(2)$ & .004 \\
Atrial fibrillation during stay & $155(17)$ & $128(14)$ & .08 \\
Postoperative ventilation (h) & $25.1 \pm 96.2$ & $25.3 \pm 112.0$ & .98 \\
Length of stay (d) $\dagger$ & $5[4]$ & $4[4]$ & $<.001$ \\
Readmissions $<30 \mathrm{~d}$ & $109(12)$ & $57(6)$ & $<.001$ \\
Operative death $<30 \mathrm{~d}$ & $14(2)$ & $13(1)$ & .85 \\
\hline
\end{tabular}

*Data are presented as mean \pm standard deviation or $\mathrm{N}(\%)$. $\dagger$ Median [interquartile range], evaluated with Mann-Whitney test.
No differences were found for operative mortality, deep sternal wound infections, or permanent strokes, and the incidence of these events was relatively low for both groups (Table 3). Similar 1-year cumulative survival was documented for the 2006 and 2009 cohorts (95.5\% vs $95.4 \%, \log$ rank $=0.03, P=.859$ ) (Figure 2 ), as well as similar 5-year cumulative survival $(86.2 \%$ vs $86.5 \%, \log$ rank $=0.04, P=.842$ ).

Reduction in the use of blood products from 2006 to 2009 led to a significant cost savings on the institutional level. In addition, cost data were available for RBC and platelet units in this sample. Comparison of costs for the 2 patient groups revealed that for RBC costs, patients in 2006 were less likely than patients in 2009 to incur 0 USD $(55 \%$ vs $79 \%$, chi-squared $=117.3$, $P<.001)$ and more likely to incur 0 to 450 USD $(26 \%$ vs $11 \%$, chi-squared $=66.9, P<.001)$ and 450 or more USD $(20 \%$ vs $10 \%$, chi-squared $=29.7$, $P<.001)$. Similarly for platelet costs, patients in 2006 were less likely than patients in 2009 to incur 0 USD $(66 \%$ vs $86 \%$, chi-squared $=101.0, P<.001)$ and more likely to incur 0 to 1750 USD ( $16 \%$ vs $6 \%$, chi-squared $=46.9, P<.001)$ and more than 1750 USD $(19 \%$ vs $8 \%$, chi-squared $=41.1, P<.001)$. The reduction in costs occurred even though the charged cost per blood unit increased between 2006 and 2009.

\section{Stability of Transfusion After Protocol}

After implementation of the blood conservation protocol at the Inova Heart and Vascular Institute, the incidence of 


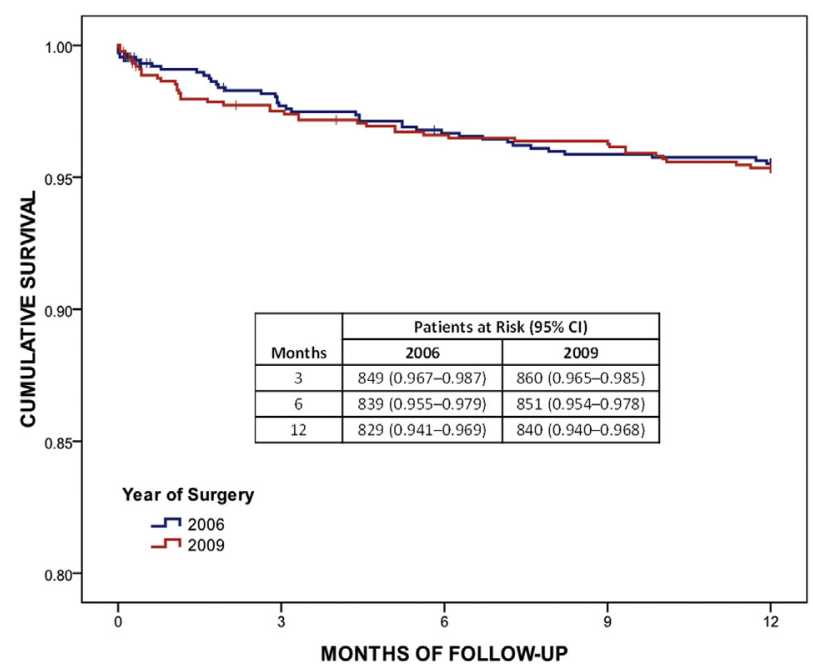

FIGURE 2. Kaplan-Meier 1-year survival curves comparing patients undergoing cardiac surgery in 2009 with patients in 2006 (Y axis scale truncated to $0.80-1.00 ; \log$-rank $=0.03, P=.859)$. $C I$, Confidence interval.

blood product transfusion in patients undergoing first-time cardiac surgery decreased significantly and has remained stable over time (Figure 3). In each year for which complete data were available after the protocol was implemented (2008-2014), the incidence of any blood product transfusion, intraoperative or postoperative, remained at $30 \%$ or less and in most years was less than $28 \%$. Most recently, in $2014,24 \%$ of patients undergoing first-time cardiac surgery received blood product transfusion during their entire hospital stay. When examined separately, intraoperative transfusion remained less than $22 \%$ and reached a low of $15 \%$ in 2013 , and postoperative transfusion remained less than $21 \%$ and reached a low of $15 \%$ in 2010 .

The greatest stability in the use of blood product transfusion since the blood protocol implementation, as well as the lowest incidence, was found for patients undergoing first-time isolated CABG surgery (Figure 4). Blood product use was highest in patients undergoing CABG and valve surgery procedures, with or without other procedures, but has steadily declined since the introduction of our blood conservation protocol. Stability in blood product use, particularly for postoperative blood product transfusion, has been lowest for patients undergoing isolated valve surgery and stand-alone or concomitant surgical ablation.

\section{DISCUSSION}

The purpose of this study was to examine the effect of an institutional blood conservation protocol on transfusion rates, patient outcomes, and costs after cardiac surgery. Nuttall and colleagues ${ }^{28}$ have demonstrated that a transfusion algorithm alone can significantly decrease transfusion rates in patients undergoing cardiac surgery;

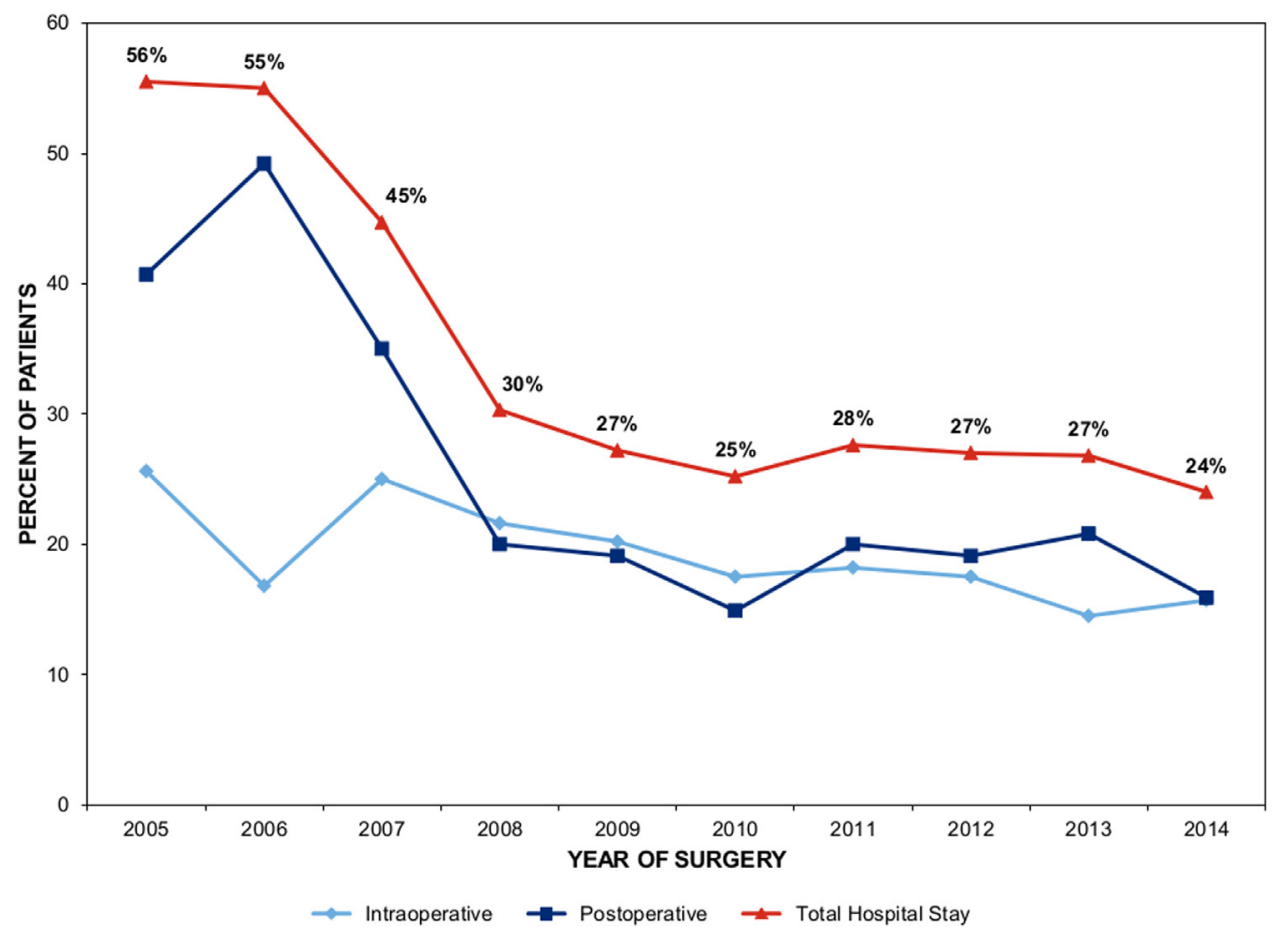

FIGURE 3. Incidence of blood product transfusion over time before and after implementation of the institutional blood administration protocol. 

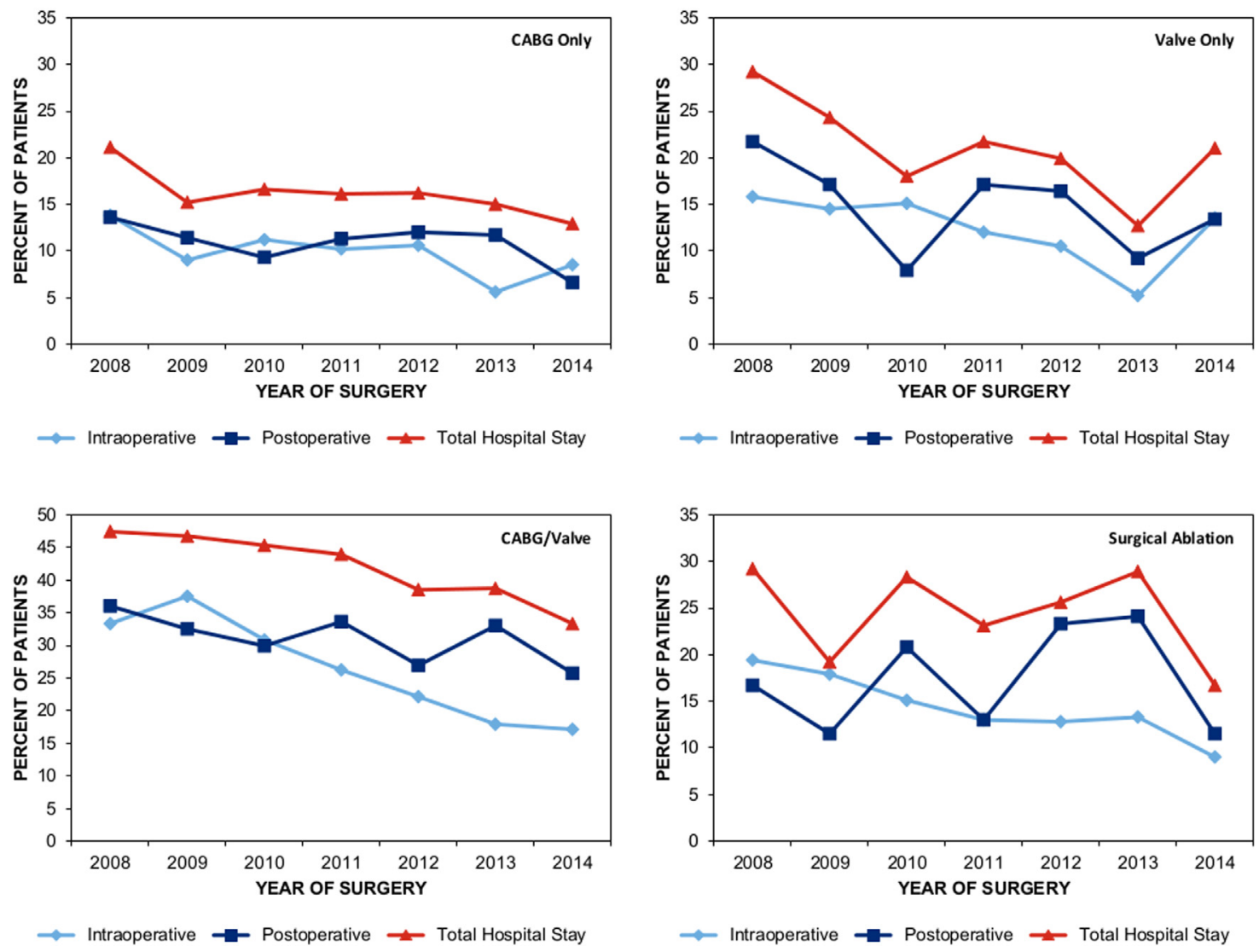

FIGURE 4. Incidence of blood product transfusion over time by surgery group after implementation of the institutional blood administration protocol. $C A B G$, Coronary artery bypass grafting.

however, we believed that the best results would be achieved through a comprehensive, multimodality approach. We found that the implementation of our protocol led to a significant decrease in the overall incidence of transfusion among patients undergoing first-time cardiac surgery at the Inova Heart and Vascular Institute. This decrease was driven mostly by changes in the postoperative period, in which a $65 \%$ decrease in transfusions was observed.

The high percentage of patients undergoing cardiac surgery receiving transfusions persists despite the efforts of the STS and the Society of Cardiovascular Anesthesiologists to promote blood conservation. ${ }^{8,14}$ This variation cannot be entirely due to differences in the clinical characteristics of patients undergoing cardiac surgery. In fact, in a recent study of more than 4000 patients undergoing cardiac surgery at a single institution, the practice patterns of individual decision makers, specifically, surgeons and anesthesiologists, were identified as greatly contributing to the significant variability in perioperative transfusion rates. ${ }^{22}$ In light of this finding, as well as those of numerous other reports, ${ }^{29-31}$ it is clear that institutions must develop and adhere to blood conservation protocols to succeed in efforts not only to reduce the incidence of blood transfusion but also to improve outcomes and minimize health care costs.

A crucial element of any successful blood conservation protocol is an appreciation for the physiology and tolerance of asymptomatic anemia. Although there is scant evidence to support definitive criteria for transfusion in certain noncritical patients, STS guidelines suggest that $\mathrm{HgB}$ levels as low as $6 \mathrm{~g} / \mathrm{dL}$ may be reasonably tolerated in certain situations before blood transfusion is ordered. ${ }^{14}$ That these recommendations are not widely adopted is mainly due to the notion that perioperative anemia may be associated with increased morbidity and mortality, as well as the perception that transfusion is safe and effective in treating anemia. ${ }^{1,18,25,32-34}$

In a multistudy review of 19 randomized controlled trials encompassing more than 6000 patients over more than 50 years, a restrictive $\mathrm{HgB}$ level cutoff was compared with a nonrestrictive cutoff. ${ }^{35}$ When a restrictive $\mathrm{HgB}$ cutoff of 7 to $10 \mathrm{~g} / \mathrm{dL}$ was applied in the review study, it resulted in conservation of approximately $1 \mathrm{RBC}$ unit of blood per patient, reduced mortality rates, and a possible reduction in the incidence of myocardial infarction. ${ }^{35}$ Otherwise, an 
HgB-restrictive approach was not shown to have a significant impact on the incidence of other complications, recovery time, or time to discharge. ${ }^{35}$ Although uncommon, the possibility of transfusion complications, such as hemolytic transfusion reactions, acute lung injury, and circulatory overload, cannot be discounted in any transfusion. $^{36}$ In addition, the benefit of a restrictive protocol may be undermined by the type of pathology present in the patient. For example, in patients with acute coronary syndrome, a restrictive $\mathrm{HgB}$ cutoff has been shown to result in increased mortality and cardiac events. $^{6,37}$

A recent study showed that a restrictive transfusion protocol, in addition to producing no harm and limiting negative outcomes, also limits costs. ${ }^{38}$ In another study, 586 patients from 2 New Jersey institutions with wellestablished blood conservation programs (the conservation cohort) were compared with a propensity score-matched cohort of 586 patients from other New Jersey institutions representing the common practice of transfusion. ${ }^{39}$ An increased incidence of complications was noted in all patients who received any blood transfusion, and there was no evidence of increased complications related to a strict transfusion protocol. ${ }^{39}$

Our finding of a decreased incidence of renal failure with blood transfusion conservation is in agreement with a previous study in which a nonanemic patient transfused with 3 units of blood was found to be approximately twice as likely as a nontransfused patient to experience acute kidney injury. ${ }^{40}$ This risk was further increased in anemic patients, who were approximately 4 times as likely to experience an acute kidney injury. ${ }^{40}$ The incidence of acute kidney injury was proportional to the amount of erythrocytes transfused. $^{40}$

Several authors have reported decreased survival for cardiac surgical patients who received a blood transfusion. ${ }^{41-43}$ This effect has been shown even in patients who received a total of 2 or less RBC units. ${ }^{44}$ One review article noted a strong association between transfusion and a wide variety of postoperative complications during the hospital stay and up to a 5-year impact on mortality rate. ${ }^{5}$

Although we did find an increase in morbidities for the patients with surgery in 2006 in our study, we also found no increase in 30-day or 1-year survival for patients before and after the blood conservation protocol was implemented. A prospective randomized controlled trial by Hajjar and colleagues ${ }^{19}$ compared liberal and strict transfusion protocols in 512 randomized cardiac surgical patients. The restrictive arm was found to be noninferior to the liberal arm for the 30-day end point, but the incidence of complications increased with each additional unit transfused. Although concerns ${ }^{45,46}$ have been raised about the noninferiority design of the study by Hajjar and colleagues, ${ }^{19}$ their results confirm the safety of strict transfusion criteria for cardiac surgical patients while providing further evidence of the deleterious effects of blood transfusion, as shown by our study.

In addition to the direct clinical benefits for our patients, the Inova Heart and Vascular Institute has realized substantial cost savings as a direct result of our protocol, as evidenced by the data presented in the current article on blood product cost. Although the complete data were not available for statistical analyses, the direct cost savings for patients undergoing $\mathrm{CABG}$ alone have been estimated by the Inova Heart and Vascular Institute's financial department at $\$ 3.75$ million per year, and the indirect cost savings from decreased morbidity rates, although difficult to quantify, could add considerably to this amount.

\section{Study Limitations}

Some limitations of our study should be noted. The use of prospectively collected data with retrospective analyses to examine effects of the blood protocol has inherent limitations. However, these limitations are minimized by the use of propensity score-matching analysis, which allowed for balanced groups across time. Moreover, clinical and cost data were collected prospectively. Therefore, data elements that would have been useful to include in these analyses, namely, preoperative $\mathrm{Hgb}$, were not available for all patients. In 2006, data were collected with the STS National Database version 2.52, which did not include Hgb, precluding it from being accounted for in the propensity score model or other analyses. It is possible that preoperative Hgb was lower for the 2009 group because they represented a sicker cohort (before matching), which could mean that blood transfusion was reduced in 2009 despite the fact that Hgb levels were lower. In addition, the fact that patients were similar on other preoperative characteristics after propensity score matching could suggest that other nonmeasured preoperative factors became balanced as well, which is a goal for this technique. However, without the data, the effect of preoperative $\mathrm{Hgb}$ has not been accounted for, and it is unclear exactly how these results are affected, which represent a limitation of this study.

Although bias in this study could not be entirely controlled because of its observational design, it was not feasible to randomize patients because the groups were surgical-year cohorts. Because of the inherent difference in surgery dates for these 2 groups, it is possible that other practice changes may have occurred in addition to the blood protocol implementation. In addition, 
subjective factors involved with the clinical decision making for patient care could have been present. However, propensity score matching was used (independently of outcomes) to reduce this temporal and clinical care bias and simulate randomization so that both unknown confounding factors and differences between the groups would be controlled for. ${ }^{47}$

\section{CONCLUSIONS}

It is troubling that despite efforts to better educate and inform practitioners about the benefits of blood conservation through clinical guidelines, ${ }^{8,14}$ a minority of practitioners seem to have implemented changes on the basis of these consensus recommendations. ${ }^{48}$ In light of the abundance of data supporting the practice of conserving blood and minimizing its use in cardiac surgery, cardiac surgery programs should consider measuring transfusion rates and indications as indicators of quality.

This study confirms the positive effect of a standardized blood conservation protocol on the postoperative outcomes of cardiac surgery. Our results and those of other researchers demonstrate the need for standardized protocols for blood transfusion at all busy cardiac surgical centers. Communication and involvement on the part of all clinicians and stakeholders involved in cardiac surgical cases are key to the success of such a protocol, and we recommend the adoption of this approach by all facilities where cardiac surgery is performed.

\section{Conflict of Interest Statement}

N.A. is a consultant for Medtronic, a member of the speaker's bureau for AtriCure, proctor and member of the speaker's bureau for LivaNova, on the advisory board for Nido Surgical, and a co-owner for Left Atrial Appendage Occlusion, LLC. All other authors have nothing to disclose with regard to commercial support.

\section{References}

1. Department of Health and Human Services. 2011 National Blood Collection and Utilization Survey Report. Available at: http://www.hhs.gov/ash/bloodsafety/ 2011-nbcus.pdf. Accessed August 25, 2015.

2. Horvath KA, Acker MA, Chang H, Bagiella E, Smith PK, Iribarne A, et al. Blood transfusion and infection after cardiac surgery. Ann Thorac Surg. 2013;95: 2194-201.

3. Mehta RH, Sheng S, O'Brien SM, Grover FL, Gammie JS, Ferguson TB, et al. Reoperation for bleeding in patients undergoing coronary artery bypass surgery: incidence, risk factors, time trends, and outcomes. Circ Cardiovasc Qual Outcomes. 2009;2:583-90.

4. Scott BH, Seifert FC, Glass PS, Grimson R. Blood use in patients undergoing coronary artery bypass surgery: impact of cardiopulmonary bypass pump, hematocrit, gender, age, and body weight. Anesth Analg. 2003;97:958-63, table of contents.

5. Reeves BC, Murphy GJ. Increased mortality, morbidity, and cost associated with red blood cell transfusion after cardiac surgery. Curr Opin Anaesthesiol. 2008; 21:669-73.

6. Murphy GJ, Reeves BC, Rogers CA, Rizvi SI, Culliford L, Angelini GD. Increased mortality, postoperative morbidity, and cost after red blood cell transfusion in patients having cardiac surgery. Circulation. 2007;116: 2544-52.

7. American College of Anesthesiologists. Practice guidelines for blood component therapy: a report by the American Society of Anesthesiologists Task Force on blood component therapy. Anesthesiology. 1996;84:732-47.

8. Society of Thoracic Surgeons Blood Conservation Guideline Task Force, Ferraris VA, Ferraris SP, Saha SP, Hessel EA II, Haan CK, Royston BD, et al. Perioperative blood transfusion and blood conservation in cardiac surgery: the Society of Thoracic Surgeons and the Society of Cardiovascular Anesthesiologists Clinical Practice Guideline. Ann Thorac Surg. 2007;83(5 Suppl):S27-86.

9. American College of Physicians. Practice strategies for elective red blood cell transfusion. American College of Physicians. Ann Intern Med. 1992; 116:403-6.

10. Canadian Medical Association. Guidelines for red blood cell and plasma transfusion for adults and children. Can Med Assoc J. 1997;156(Suppl 11): S1-25.

11. Murphy MF, Wallington TB, Kelsey P, Boulton F, Bruce M, Cohen H, et al. Guidelines for the clinical use of red cell transfusions. Br J Haematol. 2001; 113:24-31.

12. Napolitano LM, Kurek S, Luchette FA, Corwin HL, Barie PS, Tisherman SA, et al. Clinical practice guideline: red blood cell transfusion in adult trauma and critical care. Crit Care Med. 2009;37:3124-57.

13. National Institutes of Health. Perioperative red cell transfusion. National Institutes of Health Consensus Development Conference. Transfus Med Rev. 1989;3:63-8.

14. Society of Thoracic Surgeons Blood Conservation Guideline Task Force, Ferraris VA, Brown JR, Despotis GJ, Hammon JW, Reece TB, Saha SP, et al. 2011 update to the Society of Thoracic Surgeons and the Society of Cardiovascular Anesthesiologists blood conservation clinical practice guidelines. Ann Thorac Surg. 2011;91:944-82.

15. World Health Organization. Haemoglobin Concentrations for the Diagnosis of Anaemia and Assessment of Severity. Vitamin and Mineral Nutrition Information System. Geneva, Switzerland: World Health Organization; 2011.

16. Rogers MA, Blumberg N, Saint S, Langa KM, Nallamothu BK. Hospital variation in transfusion and infection after cardiac surgery: a cohort study. BMC Med. 2009;7:37.

17. Snyder-Ramos SA, Mohnle P, Weng YS, Bottiger BW, Kulier A, Levin J, et al. The ongoing variability in blood transfusion practices in cardiac surgery. Transfusion. 2008;48:1284-99.

18. Stover EP, Siegel LC, Parks R, Levin J, Body SC, Maddi R, et al. Variability in transfusion practice for coronary artery bypass surgery persists despite national consensus guidelines: a 24-institution study. Institutions of the multicenter study of perioperative ischemia research group. Anesthesiology. 1998;88:327-33.

19. Hajjar LA, Vincent JL, Galas FR, Nakamura RE, Silva CM, Santos MH, et al. Transfusion requirements after cardiac surgery: the TRACS randomized controlled trial. JAMA. 2010;304:1559-67.

20. Bennett-Guerrero E, Zhao Y, O'Brien SM, Ferguson TB Jr, Peterson ED, Gammie JS, et al. Variation in use of blood transfusion in coronary artery bypass graft surgery. JAMA. 2010;304:1568-75.

21. Surgenor DM, Churchill WH, Wallace EL, Rizzo RJ, McGurk S, Goodnough LT, et al. The specific hospital significantly affects red cell and component transfusion practice in coronary artery bypass graft surgery: a study of five hospitals. Transfusion. 1998;38:122-34.

22. Cote C, MacLeod JB, Yip AM, Ouzounian M, Brown CD, Forgie R, et al. Variation in transfusion rates within a single institution: exploring the effect of differing practice patterns on the likelihood of blood product transfusion in patients undergoing cardiac surgery. J Thorac Cardiovasc Surg. 2015;149: 297-302.

23. Bhaskar B, Dulhunty J, Mullany DV, Fraser JF. Impact of blood product transfusion on short and long-term survival after cardiac surgery: more evidence. Ann Thorac Surg. 2012;94:460-7. 
24. Murphy GJ, Pike K, Rogers CA, Wordsworth S, Stokes EA, Angelini GD, et al. Liberal or restrictive transfusion after cardiac surgery. N Engl J Med. 2015;372: 997-1008.

25. Moise SF, Higgins MJ, Colquhoun AD. A survey of blood transfusion practice in UK cardiac surgery units. Crit Care. 2001;5(Suppl A):5.

26. Ho D, Imai K, King G, Stuart E. Matching as nonparametric preprocessing for reducing model dependence in parametric causal inference. Polit Anal. 2007; 15:199-236.

27. Ho D, Imai K, King G, Stuart E. MatchIt: nonparametric preprocessing for parametric causal inference. J Stat Softw. 2011:42:1-28.

28. Nuttall GA, Oliver WC, Santrach PJ, Bryant S, Dearani JA, Schaff HV, et al. Efficacy of a simple intraoperative transfusion algorithm for nonerythrocyte component utilization after cardiopulmonary bypass. Anesthesiology. 2001;94: 773-81.

29. LaPar DJ, Crosby IK, Ailawadi G, Ad N, Choi E, Spiess BD, et al. Blood product conservation is associated with improved outcomes and reduced costs after cardiac surgery. J Thorac Cardiovasc Surg. 2013;145:796-804.

30. Brown CH IV, Savage WJ, Masear CG, Walston JD, Tian J, Colantuoni E, et al. Odds of transfusion for older adults compared to younger adults undergoing surgery. Anesth Analg. 2014;118:1168-78.

31. Yaffee DW, Smith DE III, Ursomanno PA, Hill FT, Galloway AC, DeAnda A, et al. Management of blood transfusion in aortic valve surgery: Impact of a blood conservation strategy. Ann Thorac Surg. 2014;97:95-101.

32. Sherwood MW, Wang Y, Curtis JP, Peterson ED, Rao SV. Patterns and outcomes of red blood cell transfusion in patients undergoing percutaneous coronary intervention. JAMA. 2014;311:836-43.

33. Wu WC, Rathore SS, Wang Y, Radford MJ, Krumholz HM. Blood transfusion in elderly patients with acute myocardial infarction. N Engl J Med. 2001;345: 1230-6.

34. Chatterjee S, Wetterslev J, Sharma A, Lichstein E, Mukherjee D. Association of blood transfusion with increased mortality in myocardial infarction: a meta-analysis and diversity-adjusted study sequential analysis. JAMA Intern Med. 2013;173:132-9.

35. Carson JL, Carless PA, Hebert PC. Outcomes using lower vs higher hemoglobin thresholds for red blood cell transfusion. JAMA. 2013;309:83-4.

36. Tanhehco YC, Berns JS. Red blood cell transfusion risks in patients with end-stage renal disease. Semin Dial. 2012;25:539-44.

37. Carson JL, Brooks MM, Abbott JD, Chaitman B, Kelsey SF, Triulzi DJ, et al. Liberal versus restrictive transfusion thresholds for patients with symptomatic coronary artery disease. Am Heart J. 2013;165:964-71.e1.
38. Mirski MA, Frank SM, Kor DJ, Vincent JL, Holmes DR Jr. Restrictive and libera red cell transfusion strategies in adult patients: reconciling clinical data with best practice. Crit Care. 2015;19:202.

39. Moskowitz DM, McCullough JN, Shander A, Klein JJ, Bodian CA, Goldweit RS, et al. The impact of blood conservation on outcomes in cardiac surgery: is it safe and effective? Ann Thorac Surg. 2010;90:451-8.

40. Karkouti K, Wijeysundera DN, Yau TM, McCluskey SA, Chan CT, Wong PY, et al. Influence of erythrocyte transfusion on the risk of acute kidney injury after cardiac surgery differs in anemic and nonanemic patients. Anesthesiology. 2011 115:523-30.

41. Engoren MC, Habib RH, Zacharias A, Schwann TA, Riordan CJ, Durham SJ Effect of blood transfusion on long-term survival after cardiac operation. Ann Thorac Surg. 2002;74:1180-6.

42. Koch CG, Khandwala F, Li L, Estafanous FG, Loop FD, Blackstone EH. Persistent effect of red cell transfusion on health-related quality of life after cardiac surgery. Ann Thorac Surg. 2006;82:13-20.

43. Kuduvalli M, Oo AY, Newall N, Grayson AD, Jackson M, Desmond MJ, et al Effect of peri-operative red blood cell transfusion on 30-day and 1-year mortality following coronary artery bypass surgery. Eur J Cardiothorac Surg. 2005;27: 592-8.

44. Surgenor SD, Kramer RS, Olmstead EM, Ross CS, Sellke FW, Likosky DS et al. The association of perioperative red blood cell transfusions and decreased long-term survival after cardiac surgery. Anesth Analg. 2009; 108:1741-6.

45. McIlroy D, Argenziano M. Blood transfusion and cardiac surgery. JAMA. 2011 305:357.

46. Shehata N, Mazer CD, Thorpe KE. Blood transfusion and cardiac surgery. JAMA. 2011:305:357-8.

47. Pattanayak CW, Rubin DB, Zell ER. Propensity score methods for creating covariate balance in observational studies. Rev Esp Cardiol. 2011;64 897-903.

48. Likosky DS, FitzGerald DC, Groom RC, Jones DK, Baker RA, Shann KG, et al Effect of the perioperative blood transfusion and blood conservation in cardiac surgery clinical practice guidelines of the Society of Thoracic Surgeons and the Society of Cardiovascular Anesthesiologists upon clinical practices. Anesth Analg. 2010;111:316-23.

Key Words: blood transfusion, cardiac surgery, patient outcomes 
Distribution of Propensity Scores

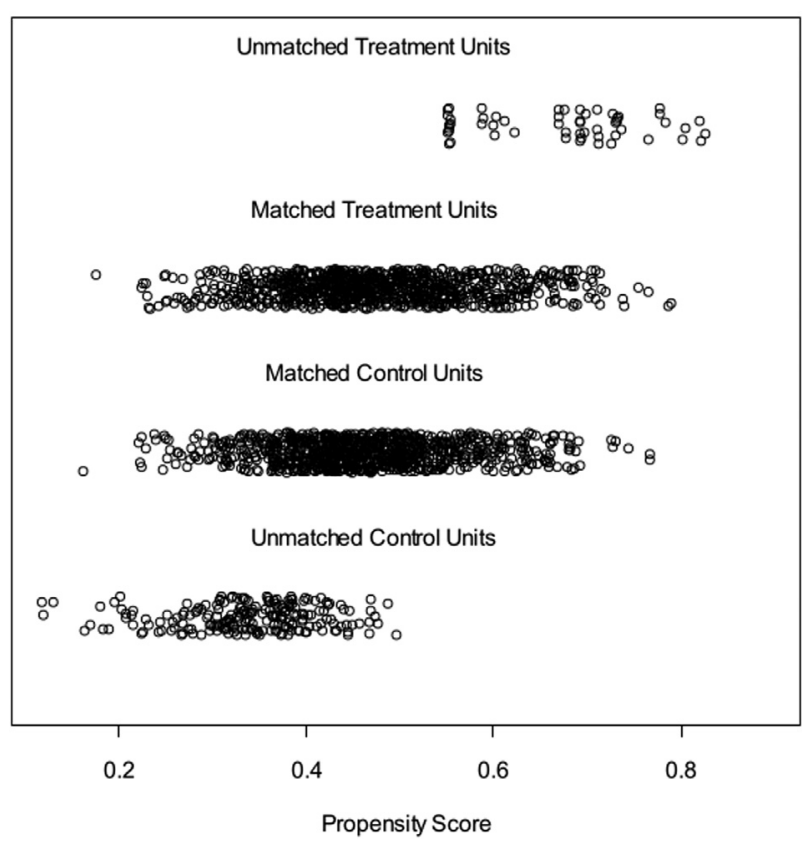

FIGURE E1. Jitter plot demonstrating the distribution of propensity scores for 2009 (treatment units) and 2006 (control units). 